\title{
ANÁLISIS DE RESILIENCIA EN INVERSIONES DE UN SISTEMA DE RIEGO EN BASE A LA COMPARACIÓN DE ESCENARIOS DE CAMBIO CLIMÁTICO
}

\author{
Fabiola Azcuña Castro y Dayana Estela Mejía Vaca
}

\section{RESUMEN}

El presente documento refleja un Análisis de Resiliencia en Inversiones (ARI) de un sistema de riego para la Comunidad Cauchi Titiri, de acuerdo a la comparación de escenarios de cambio climático (CCSM4 y MIROC), y un análisis de variabilidad de la temperatura y precipitación, considerando los escenarios de trayectorias de concentración representativas (RCP): 2.6_2020; 4.5_2050 y 8.5_2050. Esta zona presenta inundaciones, sequías, heladas y granizadas; además está situado en un área semi árida, donde existe un nivel medio de amenaza en cuanto a sequías, presentando un alto déficit hídrico. Por consiguiente, se requiere la implementación de un sistema de riego que coadyuve a mejorar el rendimiento de la producción agrícola y garantice la disponibilidad de agua para riego en la zona. Los resultados obtenidos de este análisis indican que existirá un incremento de amenaza de sequías y heladas, considerados como riesgos principales para el ARI. Este análisis está basado en tres módulos de estudio, Análisis de Riesgos, Análisis de Resiliencia Climática y Análisis de Beneficio/Costo, se plantearon medidas de mitigación de exposición al riesgo, como ser, cambiar la ubicación del atajado y fortalecer no sólo las capacidades de limpieza del sistema de riego, sino también la capacidad de atender eventos de cambio climático. Por lo tanto, se logrará una reducción del riesgo del sistema en un $40 \%$, considerando el riesgo actual y el riesgo con incidencia al cambio climático. Por su parte, se alcanzará un costo evitado de Bs. 1.526.668 por pérdidas de reconstrucción y atención a la emergencia.

Palabras Clave: Cambio Climático, Análisis de Resiliencia en Inversiones (ARI), Mitigación, Resiliencia, Trayectorias de Concentración Representativas (RCP), Modelos Climáticos, Sistema de riego.

DOI: 10.23881/idupbo.021.1-4i 